\title{
Erratum to: Presence of a short repeat sequence in internal transcribed spacer (ITS) 1 of the rRNA gene of Sogatella furcifera (Hemiptera: Delphacidae) from geographically different populations in Asia
}

\author{
Qiang Fu • Yukiko Matsumoto - Masaya Matsumura • \\ Yoshio Hirai · Yuki Sato • Hiroaki Noda
}

Published online: 17 August 2012

(C) The Japanese Society of Applied Entomology and Zoology 2012

Erratum to: Appl Entomol Zool (2012) 47:95-101

DOI 10.1007/s13355-012-0093-y

The original publication of the article is published in volume 47, 2012 pages ranging from 95 to 101. The "six countries" in the eighth line of abstract (page 95, left column) and in the third line of third paragraph (page 100, left column) should actually read as "six regions".

The online version of the original article can be found under doi:10.1007/s13355-012-0093-y.

Q. Fu

China National Rice Research Institute, Hangzhou, China

Y. Matsumoto $\cdot$ Y. Sato $\cdot$ H. Noda $(\bowtie)$

National Institute of Agrobiological Sciences,

Ibaraki 305-8634, Japan

e-mail: hnada@affrc.go.jp

M. Matsumura

National Agricultural Research Center for Kyushu Okinawa

Region, Koshi, Kumamoto 861-1192, Japan

Y. Hirai

7-12-11 Sena, Aoi, Shizuoka, Shizuoka 420-0912, Japan 